Received: 23 October 2017

Accepted: 5 November 2018

Published online: 21 December 2018

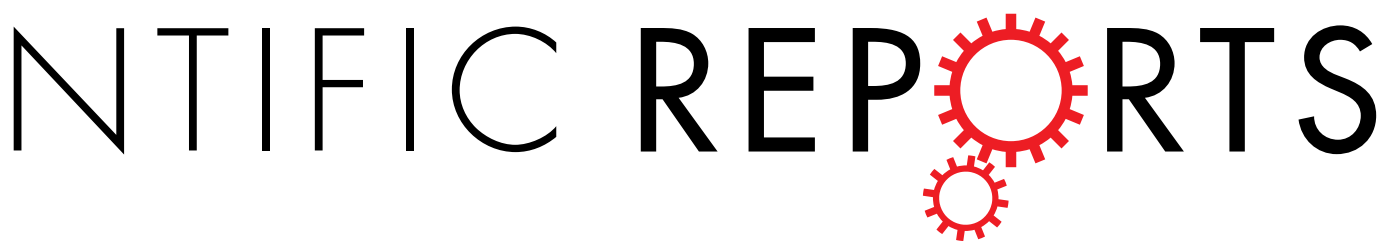

\title{
Freestanding Three-Dimensional CuO/NiO Core-Shell Nanowire Arrays as High-Performance Lithium-Ion Battery Anode
}

\author{
Yin-Wei Cheng ${ }^{1}$, Chun-Hung Chen ${ }^{1}$, Shu-WeiYang ${ }^{1}$, Yi-Chang Li $^{1}$, Bo-Liang Peng ${ }^{1}$, \\ Chia-Chin Chang ${ }^{2}$, Ruey-Chi Wang ${ }^{3} \&$ Chuan-Pu Liu ${ }^{1}$
}

We demonstrate significant improvement of CuO nanowire arrays as anode materials for lithium ion batteries by coating with thin $\mathrm{NiO}$ nanosheets conformally. The NiO nanosheets were designed two kinds of morphologies, which are porous and non-porous. By the NiO nanosheets coating, the major active $\mathrm{CuO}$ nanowires were protected from direct contact with the electrolyte to improve the surface chemical stability. Simultaneously, through the observation and comparison of TEM results of crystalline non-porous NiO nanosheets, before and after lithiation process, we clearly prove the effect of expected protection of CuO, and clarify the differences of phase transition, crystallinity change, ionic conduction and the mechanisms of the capacity decay further. Subsequently, the electrochemical performances exhibit lithiation and delithiation differences of the porous and non-porous $\mathrm{NiO}$ nanosheets, and confirm that the presence of the non-porous $\mathrm{NiO}$ coating can still effectively assist the diffusion of $\mathrm{Li}+$ ions into the $\mathrm{CuO}$ nanowires, maintaining the advantage of high surface area, and improves the cycle performance of CuO nanowires, leading to enhanced battery capacity. Optimally, the best structure is validated to be non-porous $\mathrm{NiO}$ nanosheets, in contrary to the anticipated porous $\mathrm{NiO}$ nanosheets. In addition, considering the low cost and facile fabrication process can be realized further for practical applications.

Lithium-ion battery (LIB) is one of the dominant power sources for electric vehicles, medical devices, and personal electronics due to the long cycle life, high-energy density, and light weight. However, to meet the future high-energy demands needed by high-performance electric vehicles, electronics and medical devices, extensive research efforts have been directed toward the search of new anode materials of higher capacity as well as low-cost and long-term stability.

Thus far, graphite is the most common anode material, the theoretical capacity of which is limited to $372 \mathrm{mAh} \mathrm{g}^{-1}$. As such, various new anode materials have been studied for enhancing the performance of LIBs, such as CuO, $\mathrm{NiO}, \mathrm{Fe}_{2} \mathrm{O}_{3}, \mathrm{TiO}_{2}, \mathrm{SnO}_{2}$, and $\mathrm{Si}^{1-35}$. Unfortunately, these anode materials have shortcomings as well, including low conductivity, excessive volume expansion during cycling, and low capacity, among others, thereby demanding more research. Among the above candidates, $\mathrm{CuO}$ stands out as probably the best compromise between high theoretical capacity, long cycle life and low cost for replacing graphite as the next generation anode material. Therefore, $\mathrm{CuO}$ has received extensive attention due to its relatively high theoretical capacity of $674 \mathrm{mAh} \mathrm{g}^{-1}$ (80\% more than graphite), low raw materials cost and straightforward synthesis. Nevertheless, serious drawbacks for $\mathrm{CuO}$ remain, including problems in volume expansion and high irreversible insertion of lithium, which causes rapid degradation in capacity and cycle life. In response, many research groups have aimed at solving these problems by developing various heterogeneous nanostructures, nanowires, nanoparticles, and dendritic structures ${ }^{2-14}$.

Yet, $\mathrm{CuO}$ nanowires have been predominantly synthesized by a hydrothermal method at low temperatures, which offers the advantages of low cost but at the expense of crystallinity and adhesion ${ }^{5,8,16}$. The low crystallinity and poor adhesion leads to poor conductivity and LIB lifetime. Accordingly, attempts via annealing processes,

${ }^{1}$ Department of Materials Science and Engineering, National Cheng Kung University, Tainan, 70001, Taiwan. ${ }^{2}$ Department of Greenergy, National University of Tainan, Tainan, 70005, Taiwan. ${ }^{3}$ Department of Chemical and Materials Engineering, National University of Kaohsiung, Kaohsiung, 81148, Taiwan. Correspondence and requests for materials should be addressed to C.-P.L. (email: cpliu@mail.ncku.edu.tw) 

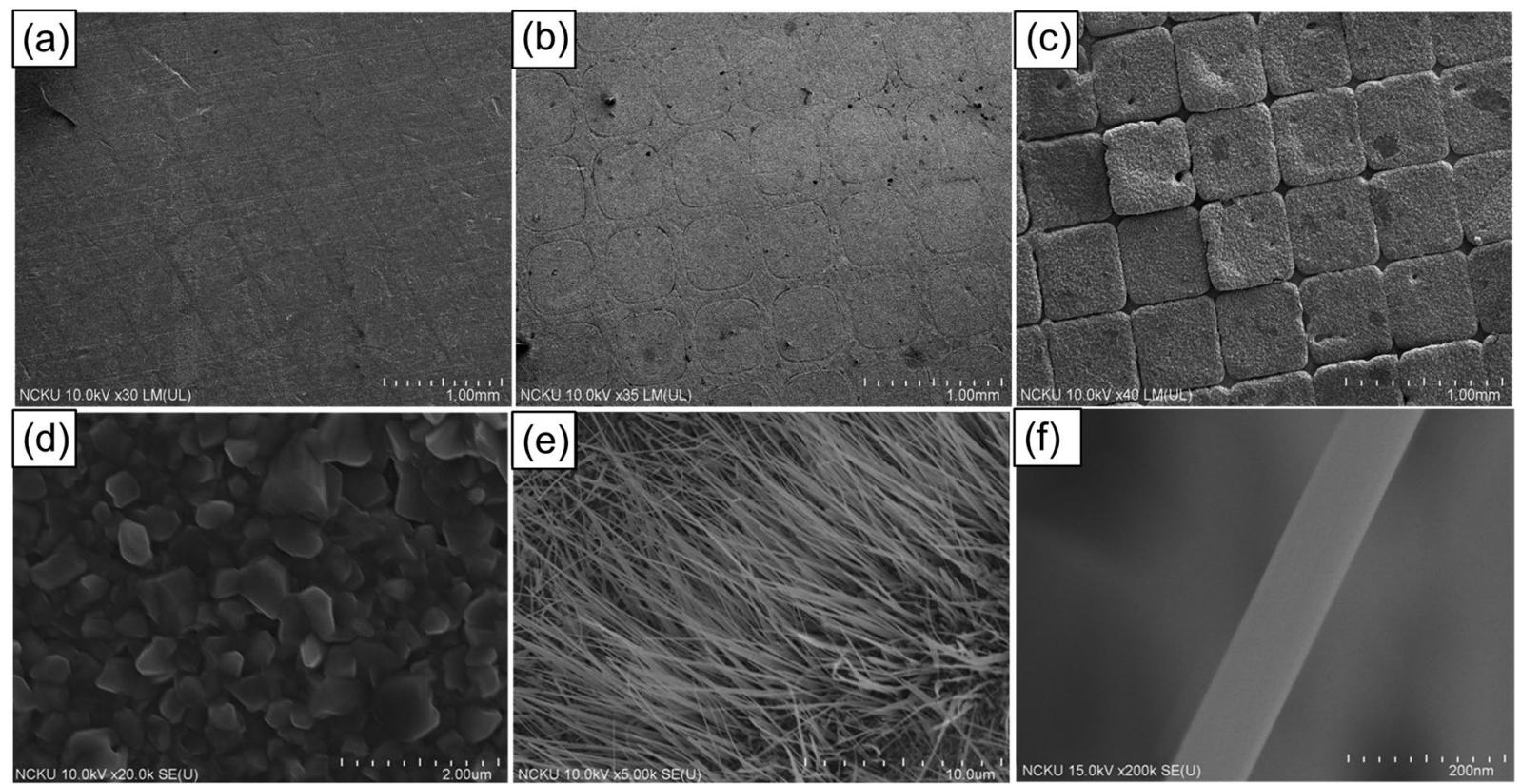

Figure 1. SEM images of (a) nickel pattern, (b) copper pattern, (c) $\mathrm{CuO}$ nanowire arrays pattern, (d) $\mathrm{CuO}$ nanoparticles in gap region, (e) $\mathrm{CuO}$ nanowires, and (f) close-up image of a single $\mathrm{CuO}$ nanowire in a grid region.

additional conductive materials, and adhesive agents have been employed to respectively increase the crystallinity, conductivity, and adhesion to enhance LIB performance $e^{1,3,9,15}$. However, due to the formation of the unwanted $\mathrm{Cu}_{2} \mathrm{O}$ phase and the expensive process involved, capacity decay and high cost still remain. Consequently, $\mathrm{CuO}$ cannot be realized as a practical anode material until these problems are resolved.

In this paper, we first develop a facile process for synthesizing patterned $\mathrm{CuO}$ nanowires, with the aim of reducing the adverse effect of volume expansion; this is followed by coating the $\mathrm{CuO}$ nanowires with $\mathrm{NiO}$ nanosheets. NiO has several exciting advantages such as low cost, easy manufacturing, environmental friendliness, and high capacity. Several $\mathrm{NiO}$ nano-structures such as nanosheets, nanoparticles, nanomembranes, and nanofibers have been demonstrated with high reversible capacities even achieving 800-1000 $\mathrm{mAh} \mathrm{g}^{-1}$ with favorable cycle life ${ }^{36-42}$. Therefore, the $\mathrm{CuO}$ nanowires with $\mathrm{NiO}$ nanosheets form a hierarchical structure to decrease the irreversible reactions while maintaining high capacity.

Subsequently, the dependence of porosity of $\mathrm{NiO}$ nanosheets on LIB performance is discussed, through which the optimal anode structure is demonstrated to be $\mathrm{CnO}$ nanowires coated with thin non-porous $\mathrm{NiO}$ nanosheets. The proposed method allows not only a stable solid-electrolyte interface layer to form, thereby benefitting to long cycle life, but also easy to implement, which is promising for mass production.

\section{Results and Discussion}

Upon thermal oxidation, the $\mathrm{Cu}$ film sequentially turned into $\mathrm{Cu}_{2} \mathrm{O}$ and $\mathrm{CuO}$, and formed a $\mathrm{CuO} / \mathrm{Cu}_{2} \mathrm{O} / \mathrm{Cu}$ stacked film structure. Subsequently, single crystalline $\mathrm{CuO}$ nanowires emerged from the top of the stacked film via a stress-assisted growth mechanism. Nevertheless, it has been reported that the CuO layer easily peels off from the underlying $\mathrm{Cu}_{2} \mathrm{O}$ layer because of the presence of significant stress induced by the large mismatch in lattice constants and thermal expansion coefficients ${ }^{43-47}$. In the present work, we demonstrate the successful growth of large area $\mathrm{CuO}$ nanowire arrays with structural integrity by patterning. Figure 1a,b, present the SEM images of the $\mathrm{Ni}$ and $\mathrm{Cu}$ patterns, respectively. As can be seen, the pattern size remains almost the same after Cu electroplating, except that the pattern shape became rounded. Upon thermal oxidation, the patterns assist in effectively relieving the film stress by reserving a gap space for volume swelling, as shown in Fig. 1c, which prevents the $\mathrm{CuO}$ film with $\mathrm{CuO}$ nanowire arrays from peeling off. Moreover, the pattern is designed to achieve the maximum possible volume density of $\mathrm{CuO}$ nanowires without leaving any gaps during the $\mathrm{CuO}$ nanowires growth, which is evidenced by the grids nearly touching each other on the sides after volume swelling in Fig. 1c.

The distribution and morphology of the resulting $\mathrm{CuO}$ nanowires are examined in Fig. $1 \mathrm{~d}-\mathrm{f}$ of the SEM images. Figure 1e.f show that dense $\mathrm{CuO}$ nanowires are only grown on the top of the $\mathrm{CuO} / \mathrm{Cu}{ }_{2} \mathrm{O} / \mathrm{Cu}$ stacked film. All the nanowires are rather dense, long and vertically aligned, as opposed to only $\mathrm{CuO}$ particles grown in the gap region shown in Fig. 1d. Figure 1f shows a typical $\mathrm{CuO}$ nanowire with a diameter between $60-80 \mathrm{~nm}$. The grazing angle XRD patterns in the supporting information (Fig. S1) show that three phases coexist, including monoclinic $\mathrm{CuO}$ nanowires, a cubic-structure $\mathrm{Cu}_{2} \mathrm{O}$ film, and a face-centered-cubic $\mathrm{Cu}$ film, which together confirm the crystal phases of the stacked film. Additionally, $\mathrm{CuO}$ nanowires exhibit single and twin crystal structures, as shown in TEM images and diffraction patterns of Fig. S2 in the supporting information. 

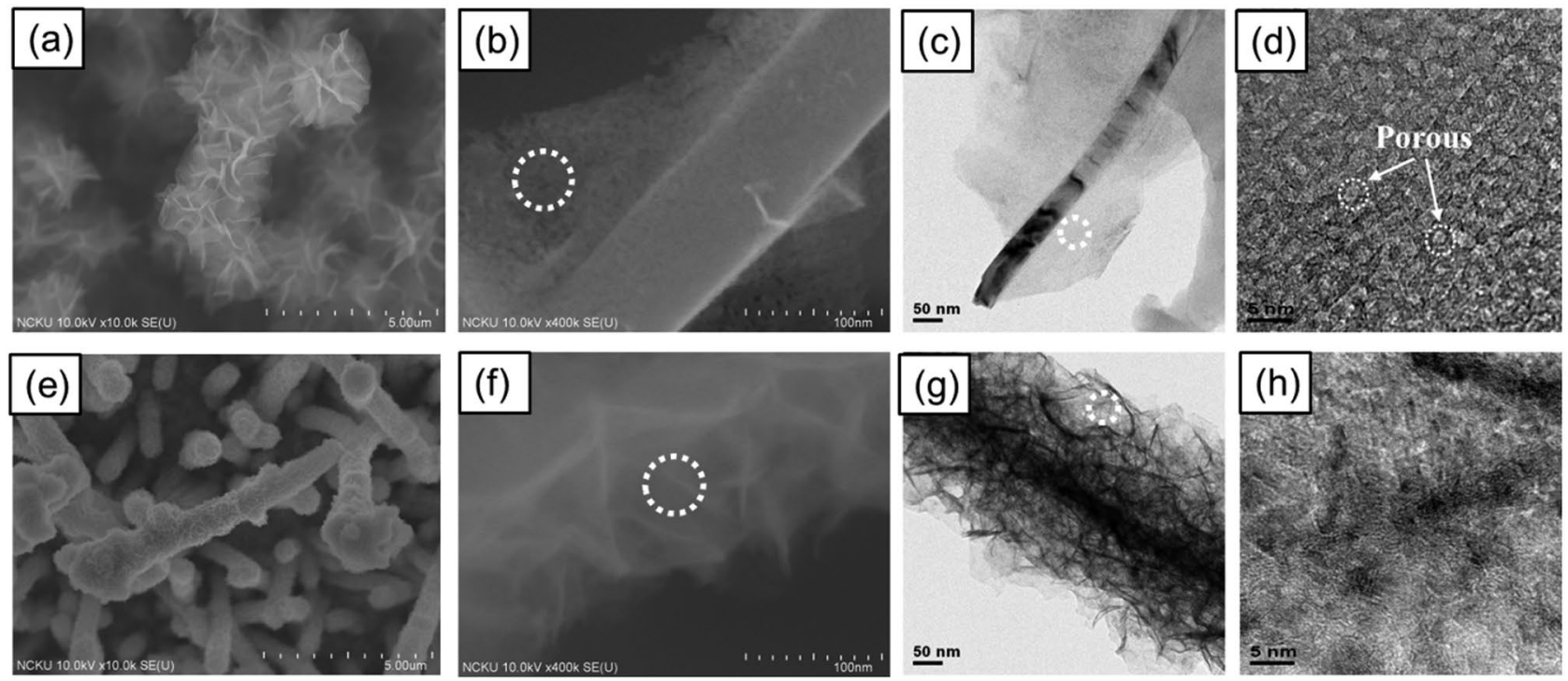

Figure 2. SEM images of the as-grown $\mathrm{NiO}$ nanosheets on the surface of the $\mathrm{CuO}$ nanowires by a hydrothermal method using precursors of $(\mathbf{a}-\mathbf{d}) \mathrm{Ni}\left(\mathrm{NO}_{3}\right)_{2},(\mathbf{e}-\mathbf{h}) \mathrm{NiSO}_{4}$, forming different morphologies, where $(\mathbf{d}, \mathbf{h})$ are the HRTEM images of the white dotted circle in $(\mathbf{b}, \mathbf{f})$, exhibiting porous and non-porous structures, respectively.

$\mathrm{NiO}$ nanosheets were grown on the surface of the $\mathrm{CuO}$ nanowires via a hydrothermal method. On examining the morphologies of the as-grown NiO nanosheets by SEM and TEM in Fig. 2, it can be seen that two drastically different morphologies were formed. As shown in Fig. 2a,c, bigger pieces of NiO nanosheets completely cover the surfaces of bundles of $\mathrm{CuO}$ nanowires by using $\mathrm{Ni}\left(\mathrm{NO}_{3}\right)_{2}$ precursors, where individual $\mathrm{NiO}$ nanosheets are composed of densely populated tiny pores measuring a few nanometers, as revealed in the HRTEM images of Fig. $2 \mathrm{~b}$, d by slight defocus. By contrast, when using $\mathrm{NiSO}_{4}$ precursors, the $\mathrm{NiO}$ nanosheets form smaller pieces and conformally coat the surface of individual $\mathrm{CuO}$ nanowires, as shown in Fig. 2e,g, where individual NiO nanosheets are non-porous, as shown in Fig. $2 \mathrm{f}$ and h. Before lithiation, the TEM images and diffraction patterns of $\mathrm{CuO} / \mathrm{NiO}\left(\mathrm{Ni}\left(\mathrm{NO}_{3}\right)_{2}\right)$ and $\mathrm{CuO} / \mathrm{NiO}\left(\mathrm{NiSO}_{4}\right)$ nanowires as shown in Fig. 3a-d indicate no $\mathrm{Cu}_{2} \mathrm{O}$ present in these nanowires. The STEM EDX maps in Fig. S3 of the supporting information reveal clearly that $\mathrm{CuO}$ and $\mathrm{NiO}$ are distributed in the cores and surfaces, respectively, of the $\mathrm{CuO} / \mathrm{NiO}\left(\mathrm{NiSO}_{4}\right)$ and $\mathrm{CuO} / \mathrm{NiO}\left(\mathrm{Ni}\left(\mathrm{NO}_{3}\right)_{2}\right.$ nanowires.

During synthesis, smaller $\mathrm{NO}^{3-}$ molecules can more easily intercalate inside the nanosheets than larger $\mathrm{SO}_{4}{ }^{2-}$ molecules, which leads to the formation of tiny pores by the evaporation of the $\mathrm{NO}^{3-}$ molecules upon subsequent thermal annealing ${ }^{48}$. Growth of the $\mathrm{NiO}$ phase in both the $\mathrm{CuO} / \mathrm{NiO}\left(\mathrm{NiSO}_{4}\right)$ and $\mathrm{CuO} / \mathrm{NiO}\left(\mathrm{Ni}\left(\mathrm{NO}_{3}\right)_{2}\right.$ nanosheets is clearly observed in the XRD patterns in Fig. $\mathrm{S} 4$ of the supporting information. According to the results of the TEM diffraction patterns in Fig. 3, the $\mathrm{Cu}_{2} \mathrm{O}$ peaks in the XRD patterns of $\mathrm{S} 4$ should originate from the remaining $\mathrm{Cu}_{2} \mathrm{O}$ film underneath instead of the $\mathrm{CuO} / \mathrm{NiO}$ nanowires. For comparison, $\mathrm{NiO}$ nanosheets were also grown on only a pure stainless steel substrate without $\mathrm{CuO}$ nanowires by using $\mathrm{NiSO}_{4}$ precursors. As shown in the SEM images of different magnifications in the supporting information (Fig. S5a-d), the substrate is covered by spheroidic particles, which are composed of self-assembled $\mathrm{NiO}$ nanosheets, in close resemblance to the morphology of the $\mathrm{NiO}$ nanosheets of the $\mathrm{CuO} / \mathrm{NiO}$ nanowires in Fig. $2 \mathrm{f}$. However, the poor contact leads to incomplete coverage on the stainless steel substrate shown in Fig. S5a.

The electrochemical performances of the $\mathrm{LIB}$ coin cells made of $\mathrm{CuO}, \mathrm{CuO} / \mathrm{NiO}\left(\mathrm{Ni}\left(\mathrm{NO}_{3}\right)_{2}\right), \mathrm{CuO} /$ $\mathrm{NiO}\left(\mathrm{NiSO}_{4}\right)$, and $\mathrm{NiO}\left(\mathrm{NiSO}_{4}\right)$ nanowire arrays are compared in Fig. 4. The CuO nanowires coin cell, shown in Fig. $4 \mathrm{a}, \mathrm{b}$ exhibits the typically fast-fading behaviors in cycle retention along with the fast-disappearing voltage plateau during the lithiation and delithiation cycles, although reasonably high capacity can be initially achieved. The capacity decay is caused by two mechanisms. First, the $\mathrm{CuO}$ nanowires suffer from volume expansion/contraction during periodic lithiation/delithiation leading to the formation of fractures, which may allow the electrolyte to permeate through the cracks inside the nanowires and form fresh solid-electrolyte-interphase (SEI) layers. The SEI may further induce more stress ${ }^{49,50}$, thereby facilitating further facture of the CuO nanowires. Second, owing to the incomplete oxidation reaction of $\mathrm{Cu}$ during the delithiation process, lower capacity $\mathrm{Cu}_{2} \mathrm{O}$ gradually forms in replace of high capacity $\mathrm{CuO}^{14}$. The $\mathrm{CuO} \mathrm{LIB}$ performance can be significantly improved by coating $\mathrm{NiO}$ nanosheets in both cases of the $\mathrm{CuO} / \mathrm{NiO}\left(\mathrm{Ni}\left(\mathrm{NO}_{3}\right)_{2}\right)$ and $\mathrm{CuO} / \mathrm{NiO}\left(\mathrm{NiSO}_{4}\right)$, as shown in Fig. $4 \mathrm{c}-\mathrm{f}$. The overall reactions of $\mathrm{CuO}$ and $\mathrm{NiO}$ during lithiation/delithiation are given by Eqs $(1)$ and $(2)^{8,51}$ :

$$
\begin{gathered}
\mathrm{CuO}+2 \mathrm{Li}^{+}+2 \mathrm{e}^{-} \leftrightarrow \mathrm{Li}_{2} \mathrm{O}+\mathrm{Cu} \\
\mathrm{NiO}+2 \mathrm{Li}^{+}+2 \mathrm{e}^{-} \leftrightarrow \mathrm{Ni}+\mathrm{Li}_{2} \mathrm{O}
\end{gathered}
$$

Equation (1) combines multistep electrochemical reactions as given below: 

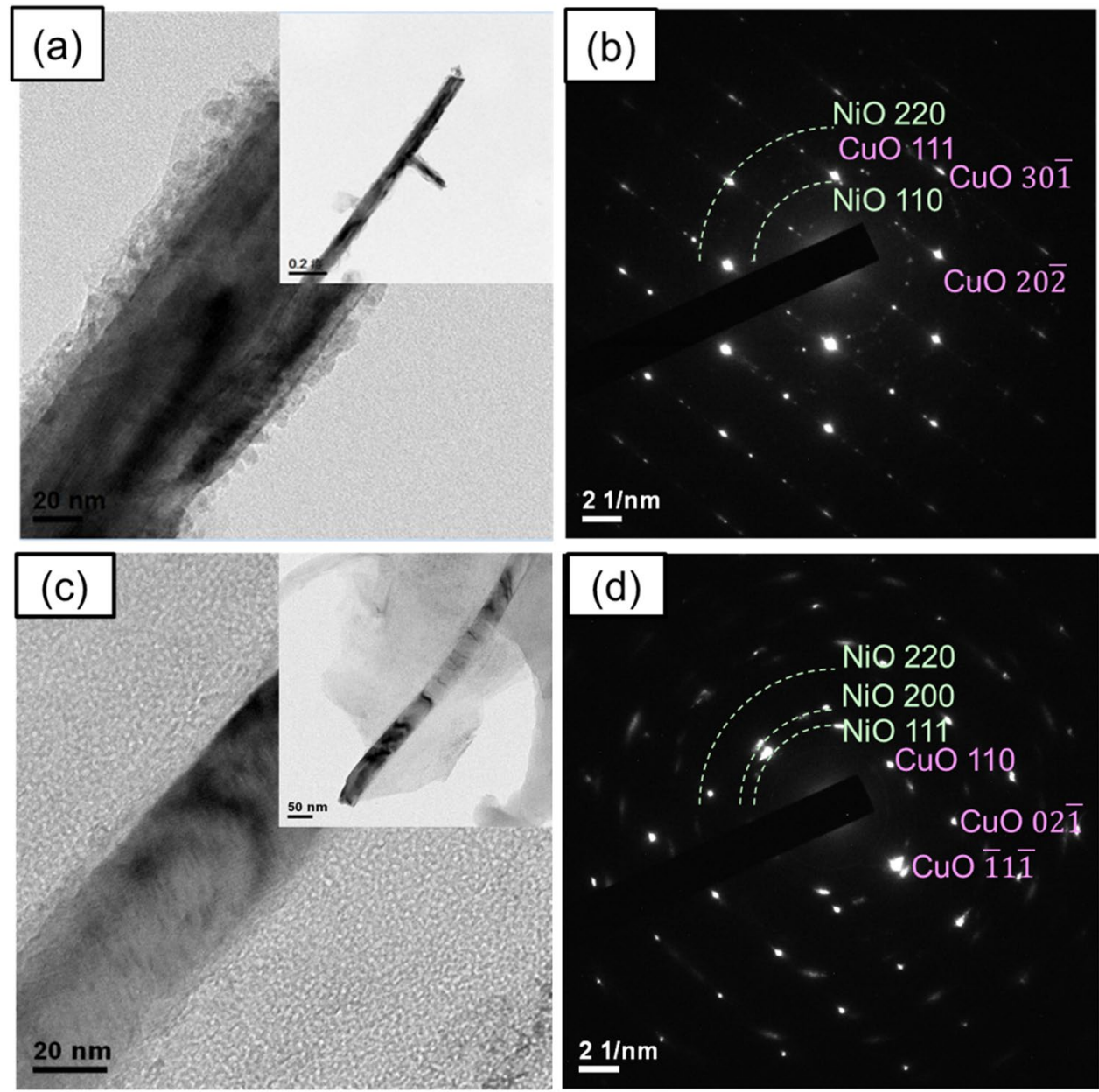

Figure 3. $\mathrm{TEM}$ analysis of the $\mathrm{CuO} / \mathrm{NiO}\left(\mathrm{NiSO}_{4}\right)$ and $\mathrm{CuO} / \mathrm{NiO}\left(\mathrm{Ni}\left(\mathrm{NO}_{3}\right)_{2}\right)$ nanowires before lithiation. (a) TEM images and (b) diffraction pattern of the $\mathrm{CuO} / \mathrm{NiO}\left(\mathrm{NiSO}_{4}\right)$ hierarchical nanowires; (c) TEM images and (d) diffraction pattern of the $\mathrm{CuO} / \mathrm{NiO}\left(\mathrm{Ni}\left(\mathrm{NO}_{3}\right)_{2}\right)$ hierarchical nanowires.

$$
\begin{gathered}
\mathrm{CuO}+\mathrm{xLi}^{+}+\mathrm{xe}^{-} \rightarrow \mathrm{Cu}_{1-\mathrm{x}}^{\mathrm{II}} \mathrm{Cu}_{\mathrm{x}}^{\mathrm{I}} \mathrm{O}_{1-\mathrm{x} / 2}+\mathrm{x} / 2 \mathrm{Li}_{2} \mathrm{O}(0<\mathrm{x}<0.4) \\
\mathrm{Cu}_{1-\mathrm{x}}^{\mathrm{II}} \mathrm{Cu}_{\mathrm{x}}^{\mathrm{I}} \mathrm{O}_{1-\mathrm{x} / 2}+(1-\mathrm{x}) \mathrm{Li}^{+}+(1-\mathrm{x}) \mathrm{e}^{-} \rightarrow 1 / 2 \mathrm{Cu}_{2} \mathrm{O}+(1-\mathrm{x}) / 2 \mathrm{Li}_{2} \mathrm{O} \\
1 / 2 \mathrm{Cu}_{2} \mathrm{O}+\mathrm{Li}^{+}+\mathrm{e}^{-} \rightarrow \mathrm{Cu}+1 / 2 \mathrm{Li}_{2} \mathrm{O}
\end{gathered}
$$

The first step (Eq. 3) shows that Li reacts with $\mathrm{CuO}$ to forms the intermediate composite copper oxide phase. In the second step (Eq. 4), the reduction reaction leads to $\mathrm{Cu}_{2} \mathrm{O}$ formation. Ultimately, $\mathrm{Cu}_{2} \mathrm{O}$ is decomposed into $\mathrm{Cu}$ and $\mathrm{Li}_{2} \mathrm{O}$ (Eq. 5) ${ }^{8}$. In the initial lithiation/delithiation curves of the $\mathrm{CuO} / \mathrm{NiO}$ anodes, we can observe two lithiation plateaus around $1.1-1.25 \mathrm{~V}$ and $0.5-0.75 \mathrm{~V}$ and two vague delithiation plateaus around 1.3 and $2.3 \mathrm{~V}$ in the $\mathrm{CuO} / \mathrm{NiO}\left(\mathrm{NiSO}_{4}\right)$. The lithiation plateaus represent insertion of lithium into $\mathrm{CuO}$ and $\mathrm{NiO}$, and the reduction of $\mathrm{Cu}^{2+}$ and $\mathrm{Ni}^{2+}$ into their metallic states with the formation of $\mathrm{Li}_{2} \mathrm{O}$. The delithiation platforms around 1.3 and $2.3 \mathrm{~V}$ can be attributed to the oxidation reactions of metallic $\mathrm{Cu}$ and $\mathrm{Ni}$, respectively ${ }^{52,53}$.

In order to further understand the lithiation/delithiation mechanism, Fig. S6 of the supporting information presents the $\mathrm{CV}$ curves of sample $\mathrm{CuO}, \mathrm{CuO} / \mathrm{NiO}\left(\mathrm{Ni}\left(\mathrm{NO}_{3}\right)_{2}\right), \mathrm{CuO} / \mathrm{NiO}\left(\mathrm{NiSO}_{4}\right)$, and $\mathrm{NiO}\left(\mathrm{NiSO}_{4}\right)$ for the first three cycles at a scan rate of $0.1 \mathrm{mV} \mathrm{s}^{-1}$ in the potential range of $0-3.0 \mathrm{~V}^{54-56}$.

In comparing the attainable maximum capacity after the first cycle, $\mathrm{CuO} / \mathrm{NiO}\left(\mathrm{Ni}\left(\mathrm{NO}_{3}\right)_{2}\right)$ is higher at $821 \mathrm{mAh}$ $\mathrm{g}^{-1}$, followed by $617 \mathrm{mAh} \mathrm{g}^{-1}$ for the $\mathrm{CuO} / \mathrm{NiO}\left(\mathrm{NiSO}_{4}\right)$ nanowires, both are closer to their theoretical capacities and outperform the $400 \mathrm{mAh} \mathrm{g}^{-1}$ of pure $\mathrm{CuO}$. This indicates that two types of $\mathrm{NiO}$ nanosheets not only contribute to part of the capacity, but also protect the core $\mathrm{CuO}$ nanowires from degradation by boosting the chemical stability of the surfaces. However, the porous $\mathrm{NiO}$ nanosheets provide the fastest ionic conduction paths through the numerous pores, thereby achieving the highest capacity as confirmed in Fig. S7 of the supporting information. In addition, the cycle retention was observed to sustain for 100 cycles at $0.1 \mathrm{C}$ rate, which can be ascribed to the effective relaxation of macrostress to maintain integrity over the entire structure. Nevertheless, the fast-fading phenomenon found in the $\mathrm{CuO}$ nanowires battery was drastically reduced by the $\mathrm{CuO} / \mathrm{NiO}\left(\mathrm{NiSO}_{4}\right)$ nanowires 

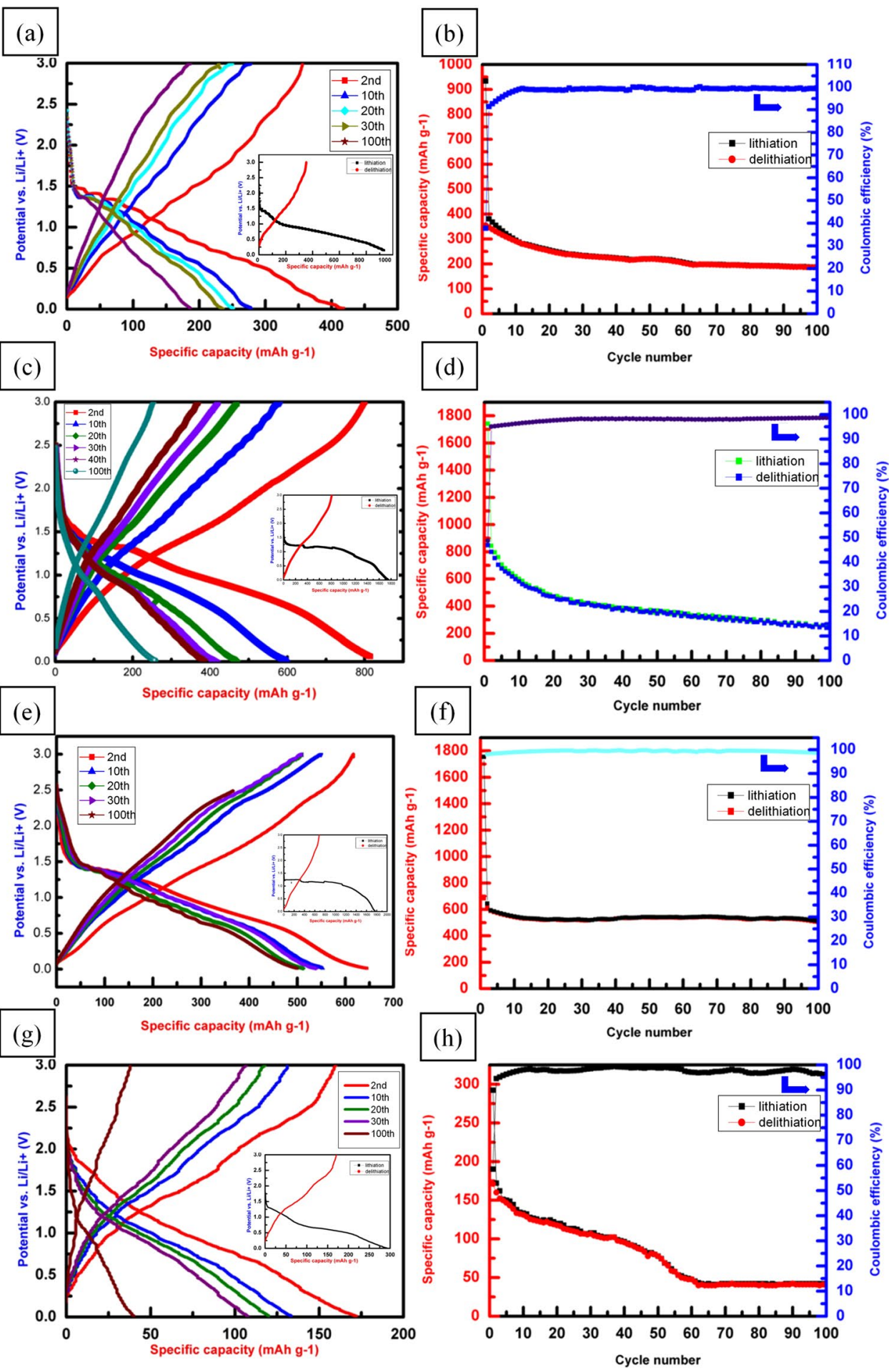

Figure 4. Electrochemical performances of $\mathrm{LIBs}$ using $(\mathbf{a}, \mathbf{b})$ pure $\mathrm{CuO},(\mathbf{c}, \mathbf{d}) \mathrm{CuO} / \mathrm{NiO}\left(\mathrm{Ni}_{(}\left(\mathrm{NO}_{3}\right)_{2}\right),(\mathbf{e}, \mathbf{f})$ $\mathrm{CuO} / \mathrm{NiO}\left(\mathrm{NiSO}_{4}\right)$ nanowires, and $(\mathbf{g}, \mathbf{h}) \mathrm{NiO}\left(\mathrm{NiSO}_{4}\right)$ sheets as anode electrodes. Please note that $(\mathbf{a}, \mathbf{c}, \mathbf{e}, \mathbf{g})$ show potentials and capacities of the lithiation/delithiation cycles, while $(\mathbf{b}, \mathbf{d}, \mathbf{f}, \mathbf{h})$ show lithiation/delithiation capacities and coulombic efficiencies for 100 cycles. The insets of $(\mathbf{a}, \mathbf{c}, \mathbf{e}, \mathbf{g})$ show the electrochemical performances of the first lithiation/delithiation cycle.

from $617 \mathrm{mAh} \mathrm{g}^{-1}$ to $522 \mathrm{mAh} \mathrm{g}^{-1}$ at $84.6 \%$ retention for 100 cycles with the best coulombic efficiency at around $98 \%$, as compared to $30.8 \%$ retention from $821 \mathrm{mAh} \mathrm{g}^{-1}$ to $253 \mathrm{mAh} \mathrm{g}^{-1}$ for the $\mathrm{CuO} / \mathrm{NiO}\left(\mathrm{Ni}\left(\mathrm{NO}_{3}\right)_{2}\right)$ battery. Therefore, the conformal coating of continuous, yet thin $\mathrm{NiO}$ nanosheets on the surface of the $\mathrm{CuO}$ nanowires promises the best route to protect them from chemical and mechanical degradation while still boosting effective capacity. The hierarchical $\mathrm{CuO} / \mathrm{NiO}$ nanowires play an important role in achieving such excellent battery performance with the $\mathrm{CuO}$ nanowires, which is evidenced by the poor battery performance of $\mathrm{NiO}\left(\mathrm{NiSO}_{4}\right)$ nanosheets 

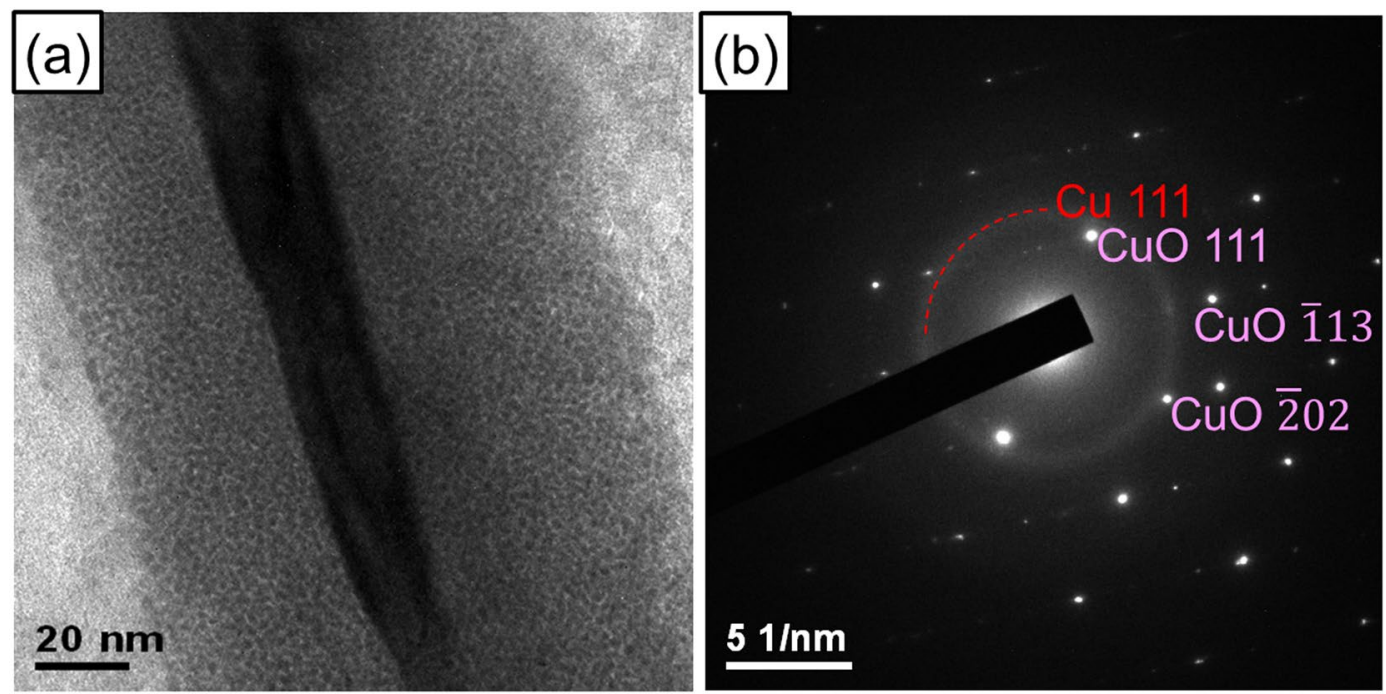

Figure 5. TEM analysis of the uncoated $\mathrm{CuO}$ nanowires upon reactions with $\mathrm{Li}$ ions during the lithiation process of the first cycle: (a) TEM image, and (b) diffraction pattern.
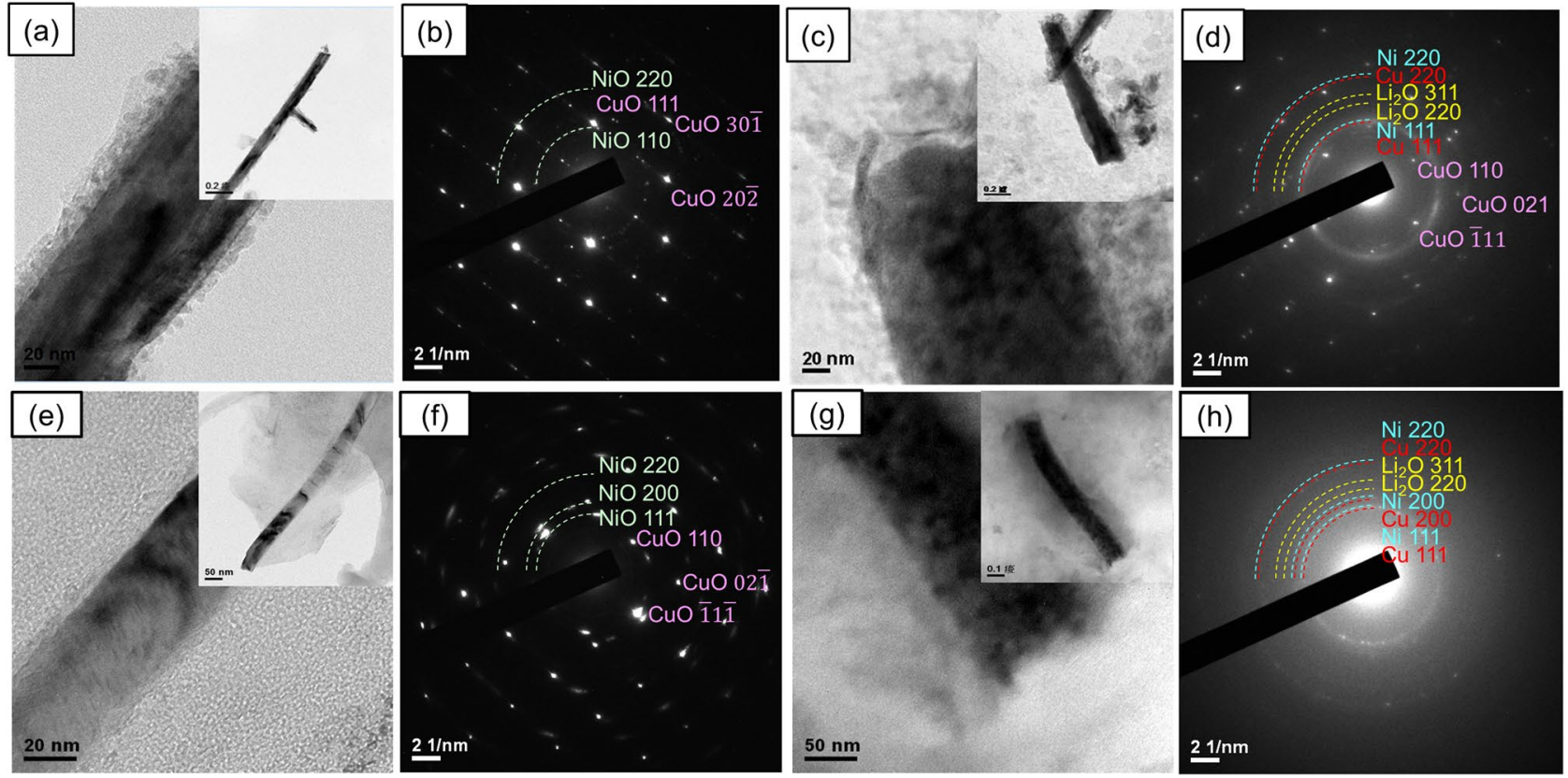

Figure 6. TEM analysis of the $\mathrm{CuO} / \mathrm{NiO}\left(\mathrm{NiSO}_{4}\right)$ and $\mathrm{CuO} / \mathrm{NiO}\left(\mathrm{Ni}\left(\mathrm{NO}_{3}\right)_{2}\right)$ nanowires before and after lithiation. (a-d) and $(\mathbf{e}-\mathbf{h})$ are for the $\mathrm{CuO} / \mathrm{NiO}\left(\mathrm{NiSO}_{4}\right)$ and $\mathrm{CuO} / \mathrm{NiO}\left(\mathrm{Ni}\left(\mathrm{NO}_{3}\right)_{2}\right)$ hierarchical nanowires, respectively, where $(\mathbf{a}, \mathbf{e})$ TEM images and $(\mathbf{b}, \mathbf{f})$ diffraction patterns before lithiation; (c,g) TEM images and $(\mathbf{d}, \mathbf{h})$ diffraction patterns upon the first cycle lithiation.

alone, as shown in Fig. 4g,h, including low capacity and poor retention likely due to the poor contact with the stainless steel substrate (see Fig. S5a).

The mechanism for the improvement of capacity and retention of the $\mathrm{CuO}$ nanowires as anode materials by coating with $\mathrm{NiO}$ nanosheets was investigated in depth by TEM. As shown in Fig. 5, the CuO nanowire has expanded in size by approximately two times upon the lithiation process at the initial cycles. At this stage, the highly crystalline $\mathrm{CuO}$ nanowire has transformed into a core/shell structure. Whereas the outer shell region appears to be non-crystalline, representing the range of chemical reactions during lithiation, the highly-crystalline core is apparently an unreacted region of only about $20 \mathrm{~nm}$ in size. The diffraction pattern in Fig. $5 \mathrm{~b}$ further reveals that tiny $\mathrm{Cu}$ clusters are uniformly imbedded inside an amorphous matrix, which is possibly a mixture of $\mathrm{Li}_{2} \mathrm{O}$ and other chemical ingredients from the electrolyte to form an SEI phase. The complex phases in the amorphous shell could impede the lithium ions from deeper diffusion, limiting the attainable capacity and leading to the higher irreversible capacity in the first cycle as well as fast capacity fading in the subsequent cycles. 


\begin{tabular}{|c|c|c|c|c|}
\hline Material & $\mathrm{CuO}$ & $\mathrm{CuO} / \mathrm{NiO}\left(\mathrm{Ni}\left(\mathrm{NO}_{3}\right)_{2}\right)$ & $\mathrm{CuO} / \mathrm{NiO}\left(\mathrm{NiSO}_{4}\right)$ & $\mathrm{NiO}\left(\mathrm{NiSO}_{4}\right)$ \\
\hline Morphology & Nanowires & Porous hierarchical Nanowires & Hierarchical nanowires & Nanosheets \\
\hline Crystal Structure & Single crystal & Hierarchical & Hierarchical & Polycrystal \\
\hline Capacity 2nd (mah g $\left.{ }^{-1}\right)$ & 400 & 821 & 617 & 160 \\
\hline Capacity 100th $\left(\mathrm{mah} \mathrm{g}^{-1}\right)$ & 192 & 253 & 522 & 40 \\
\hline Capacity Retention & $48 \%$ & $30.8 \%$ & $84.6 \%$ & $25 \%$ \\
\hline
\end{tabular}

Table 1. Comparison of material morphology, crystal structure and electrochemical performance between $\mathrm{CuO}, \mathrm{CuO} / \mathrm{NiO}\left(\mathrm{Ni}\left(\mathrm{NO}_{3}\right)_{2}\right), \mathrm{CuO} / \mathrm{NiO}\left(\mathrm{NiSO}_{4}\right)$, and $\mathrm{NiO}\left(\mathrm{NiSO}_{4}\right)$ anode electrode.

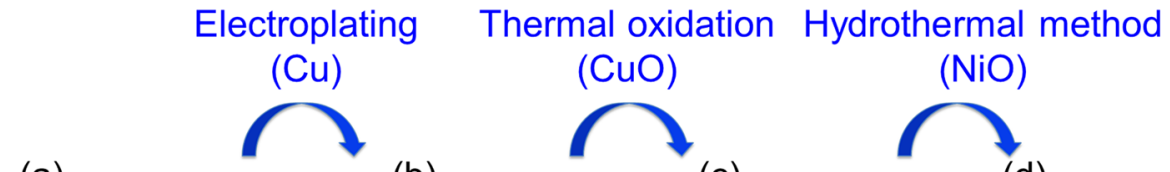

(a)

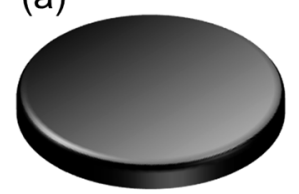

Stainless steel (b)

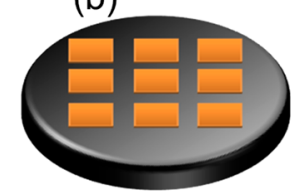

Copper pattern (c)

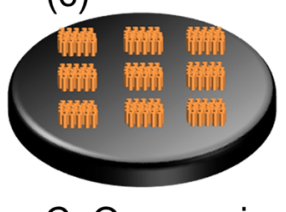

(f)

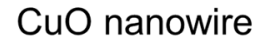

arrays

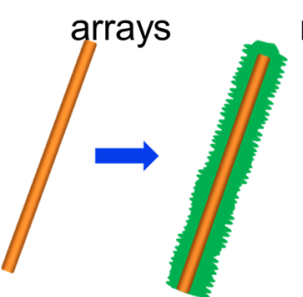

Hydrothermal method $\left(\mathrm{NiSO}_{4}\right)$ (d)

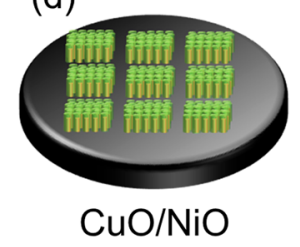

nanowire arrays (e)

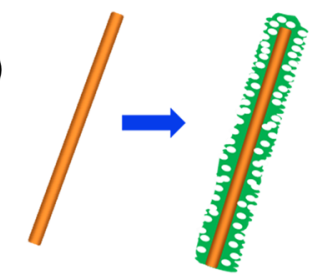

Hydrothermal method $\left(\mathrm{Ni}\left(\mathrm{NO}_{3}\right)_{2}\right)$ (f)

Figure 7. Schematic diagrams of the procedure for preparing $\mathrm{CuO} / \mathrm{NiO}$ nanowire arrays: (a) preparing the stainless steel substrate, (b) making the square $\mathrm{Cu}$ patterns, (c) growth of the $\mathrm{CuO}$ nanowire arrays by thermal oxidation, and (d) growth of the $\mathrm{NiO}$ sheets as $\mathrm{NiO} / \mathrm{CuO}$ core/shell structure by a hydrothermal method, where individual nanowires form (e) porous and (f) non-porous shells when $\mathrm{Ni}_{(}\left(\mathrm{NO}_{3}\right)_{2}$ or $\mathrm{NiSO}_{4}$ is employed as the precursor, respectively.

Figure 6a-h examine the microstructure evolution of the $\mathrm{CuO} / \mathrm{NiO}\left(\mathrm{NiSO}_{4}\right)$ and $\mathrm{CuO} / \mathrm{NiO}\left(\mathrm{Ni}\left(\mathrm{NO}_{3}\right)_{2}\right)$ nanowires respectively before and after lithiation. Consistent with the SEM images, Fig. 6a,e show that the CuO nanowires are coated with a layer of $\mathrm{NiO}$ nanosheets before electrochemical reactions. Figure $6 \mathrm{~b}, \mathrm{f}$ also confirm that the $\mathrm{NiO}$ nanosheets are polycrystalline and the core $\mathrm{CuO}$ nanowire exhibits a single crystalline structure. During the lithiation process for the first cycle, Fig. $6 \mathrm{c}$, g show that the $\mathrm{CuO}$ nanowires expand by 2 times to $220 \mathrm{~nm}$ and 3 times to $110 \mathrm{~nm}$ in the $\mathrm{CuO} / \mathrm{NiO}\left(\mathrm{NiSO}_{4}\right)$ and $\mathrm{CuO} / \mathrm{NiO}\left(\mathrm{Ni}\left(\mathrm{NO}_{3}\right)_{2}\right)$, respectively. The entire core $\mathrm{CuO}$ region has transformed into $\mathrm{Cu}$ and $\mathrm{Li}_{2} \mathrm{O}$, as confirmed by the diffraction patterns in Fig. 6d, h resulting from the lithiation of $\mathrm{CuO}$, and still predominantly remains crystalline with a clear interface with the shell. Nevertheless, the presence of $\mathrm{CuO}$ of the $\mathrm{CuO} / \mathrm{NiO}\left(\mathrm{NiSO}_{4}\right)$ nanowire after the first lithiation cycle as in Fig. $6 \mathrm{~d}$ indicates not achieving full lithiation. The outer shell region has also expanded and has become amorphous, composed of a mixture of $\mathrm{Ni}$ and SEI phases. In contrast with $\mathrm{CuO} / \mathrm{NiO}\left(\mathrm{NiSO}_{4}\right)$, Fig. $6 \mathrm{~h}$ indicates that $\mathrm{CuO} / \mathrm{NiO}\left(\mathrm{Ni}\left(\mathrm{NO}_{3}\right)_{2}\right)$ nanowire achieves full lithiation upon the first lithiation cycle due to the absence of $\mathrm{CuO}$. Therefore, the difference of crystallinity is one of the causes in the different performance between $\mathrm{CuO} / \mathrm{NiO}\left(\mathrm{Ni}\left(\mathrm{NO}_{3}\right)_{2}\right)$ and $\mathrm{CuO} / \mathrm{NiO}\left(\mathrm{NiSO}_{4}\right)$.

The TEM results suggest that the $\mathrm{NiO}$ nanosheets can isolate the active $\mathrm{CuO}$ nanowires from reactions with the electrolyte, unlike the case of the uncoated $\mathrm{CuO}$ nanowires, to form a rather stable protective layer. Simultaneously, the protective layer is thin enough for the conduction of lithium ions, allowing lithiation and delithiation of active $\mathrm{CuO}$ nanowires without any side chemical reactions with other chemical species diffused from the electrolyte. Moreover, the $\mathrm{NiO}$ nanosheets did not crack in the $\mathrm{CuO} / \mathrm{NiO}\left(\mathrm{NiSO}_{4}\right)$ nanowire and may provide a buffer for reducing the volume expansion of the $\mathrm{CuO}$ nanowire in the core. Accordingly, to the best of our knowledge, this novel structure of $\mathrm{CuO} / \mathrm{NiO}\left(\mathrm{NiSO}_{4}\right)$ scheme facilitates the active $\mathrm{CuO}$ anode materials to approach the theoretical capacity with minimal capacity decay even up to 100 cycles, which demonstrates the best performance of active $\mathrm{CuO}$ as anode materials that can be achieved for LIBs. Table 1 summarizes the material morphologies, crystal suructures, and electrochemical performances of the $\mathrm{CuO}, \mathrm{CuO} / \mathrm{NiO}\left(\mathrm{Ni}\left(\mathrm{NO}_{3}\right)_{2}\right), \mathrm{CuO} /$ $\mathrm{NiO}\left(\mathrm{NiSO}_{4}\right)$, and $\mathrm{NiO}\left(\mathrm{NiSO}_{4}\right)$ anode electrodes for comparison. 


\section{Methods}

Fabrication process of high crystalline $\mathrm{CuO}$ nanowire arrays and NiO nanosheets. Figure 7 illustrates the entire fabrication process of the $\mathrm{CuO} / \mathrm{NiO}$ nanowires for the experiment. Patterned $\mathrm{Ni}$ square arrays of $508 \mu \mathrm{m}$ in each pitch, consisting of a hole width of $425 \mu \mathrm{m}$, bar width of $83 \mu \mathrm{m}$, and a thickness of $30 \mathrm{~nm}$ were first deposited on a stainless steel sheet by precision etching and coating system (PECS) with a shadow mask of stainless steel grids. Subsequently, a $2 \mu \mathrm{m}$ thick $\mathrm{Cu}$ film was selectively grown on top of the Ni grids by $\mathrm{Cu}$ electroplating (Fig. 7b). Next, the $\mathrm{CuO}$ nanowire arrays were formed by oxidizing the $\mathrm{Cu}$ film via thermal annealing at $400^{\circ} \mathrm{C}$ for 4 hours (Fig. $7 \mathrm{c}$ ). Finally, $\mathrm{NiO}$ nanosheets were coated on the surface of the $\mathrm{CuO}$ nanowires by a hydrothermal method (Fig. 7d), in which the stainless steel sheet with $\mathrm{CuO}$ nanowire arrays was immersed in a $0.03 \mathrm{M}$ mixed solution and kept in a water bath at $85^{\circ} \mathrm{C}$ for 1 hour followed by annealing at $350^{\circ} \mathrm{C}$ for 2 hours. Figure 7e,f, show that pores may or may not form in the $\mathrm{NiO}$ nanosheets when $\mathrm{Ni}\left(\mathrm{NO}_{3}\right)_{2}$ and $\mathrm{NiSO}_{4}$ was mixed with hexamethylenetetramine (HMTA) in the solution, respectively.

Structural characterization and electrochemical measurements. The microstructure, morphology and crystallinity of the as-prepared $\mathrm{CuO}$ and $\mathrm{CuO} / \mathrm{NiO}$ nanowires were analyzed by transmission electron microscopy (TEM, JEM-2100F CS STEM, JEOL, Japan), scanning electron microscopy (SEM, SU8000, JEOL, Tokyo, Japan), and X-ray diffraction (XRD), respectively. The $\mathrm{CuO} / \mathrm{NiO}$ nanowires were assembled into coin cells as the anode for testing LIB performance. The assembling sequence from bottom to top is as follows: bottom stainless steel case, $\mathrm{Li}$ metal cathode, separator, $\mathrm{CuO} / \mathrm{NiO}$ nanowires, spring, and top stainless steel case; the electrolyte is ethylene carbonate (EC)/diethyl carbonate (DEC) with $1 \mathrm{M} \mathrm{LiPF6.} \mathrm{The} \mathrm{cycle} \mathrm{tests} \mathrm{of} \mathrm{the} \mathrm{anode}$ materials were performed between $0.1-3 \mathrm{~V}$ under a constant current of $0.1 \mathrm{C}\left(70 \mathrm{~mA} \mathrm{~g}^{-1}\right)$ at room temperature. For comparison, evolution of the morphology and microstructure of the $\mathrm{CuO} / \mathrm{NiO}$ nanowires upon cycling were studied by TEM, where a constant current of $1 \mu \mathrm{A}$ was employed for the formation process in the 1st cycle by Keithley 2400 .

\section{References}

1. Armstrong, M. J. et al. Evaluating the performance of nanostructured materials as lithium-ion battery electrodes. Nano Res. 7, 1-62 (2014).

2. Zhao, Y. et al. Epitaxial growth of hyperbranched $\mathrm{Cu} / \mathrm{Cu}_{2} \mathrm{O} / \mathrm{CuO}$ core-shell nanowire heterostructures for lithium-ion batteries. Nano Res. 8, 2763-2776 (2015).

3. Gao, X. P. et al. Preparation and electrochemical performance of polycrystalline and single crystalline CuO nanorods as anode materials for Li ion battery. J. Phys. Chem. B 108, 5547-5551 (2004).

4. Zhang, W. et al. Facile Microemulsion synthesis of porous $\mathrm{CuO}$ nanosphere film and its application in lithium ion batteries. Electrochim. Acta 113, 63-68 (2013).

5. Saadat, S. et al. Coaxial $\mathrm{Fe}_{3} \mathrm{O}_{4} / \mathrm{CuO}$ hybrid nanowires as ultra fast charge/discharge lithium-ion battery anodes. J. Mater. Chem. A 1, $8672-8678$ (2013).

6. Rai, A. K. et al. Facile approach to synthesize $\mathrm{CuO} /$ reduced graphene oxide nanocomposite as anode materials for lithium-ion battery. J. Power Sources 244, 435-441 (2013).

7. Liu, Y. et al. Flexible $\mathrm{CuO}$ nanosheets/reduced-graphene oxide composite paper: binder-free anode for high-performance lithiumion batteries. ACS Appl. Mat. Interfaces 5, 9850-9855 (2013).

8. Chen, K. \& Xue, D. Room-temperature chemical transformation route to CuO nanowires toward high-performance electrode materials. J. Phys. Chem. C 117, 22576-22583 (2013).

9. Wang, Q. et al. CuO nanorods/graphene nanocomposites for high-performance lithium-ion battery anodes. J. Alloys Compd. 590, 424-427 (2014)

10. Waser, O. et al. Size controlled CuO nanoparticles for Li-ion batteries. J. Power Sources 241, 415-422 (2013).

11. Zhu, C. et al. Enhanced lithium storage performance of $\mathrm{CuO}$ nanowires by coating of graphene quantum dots. Adv. Mater. Interfaces 2, 1400499 (2015).

12. Wang, J. et al. Three-dimensional hierarchical $\mathrm{Co}_{3} \mathrm{O}_{4} / \mathrm{CuO}$ nanowire heterostructure arrays on nickel foam for high-performance lithium ion batteries. Nano Energy 6, 19-26 (2014)

13. Feng, L. et al. Preparation of octahedral CuO micro/nanocrystals and electrochemical performance as anode for lithium-ion battery. J. Alloys Compd. 600, 162-167 (2014).

14. Wang, X. et al. Revealing the conversion mechanism of $\mathrm{CuO}$ nanowires during lithiation-delithiation by in situ transmission electron microscopy. Chem. Commun. 48, 4812-4814 (2012).

15. Xiang, J. Y. et al. Self-assembled synthesis of hierarchical nanostructured $\mathrm{CuO}$ with various morphologies and their application as anodes for lithium ion batteries. J. Power Sources 195, 313-319 (2010).

16. Chen, X., Zhang, N. \& Sun, K. Facile fabrication of CuO 1D pine-needle-like arrays for super-rate lithium storage. J. Mater. Chem. 22, 15080-15084 (2012).

17. Sahay, R. et al. High aspect ratio electrospun $\mathrm{CuO}$ nanofibers as anode material for lithium-ion batteries with superior cycleability. J. Phys. Chem. C 116, 18087-18092 (2012).

18. Wu, Z. S. et al. Graphene/metal oxide composite electrode materials for energy storage. Nano Energy 1, 107-131 (2012).

19. Sun, Z. et al. Facile fabrication of hierarchical $\mathrm{ZnCo}_{2} \mathrm{O}_{4} / \mathrm{NiO}$ core/shell nanowire arrays with improved lithium-ion battery performance. Nanoscale 6, 6563-6568 (2014).

20. Xiong, Q. Q. et al. A Three-dimensional hierarchical $\mathrm{Fe}_{2} \mathrm{O}_{3} @ \mathrm{NiO}$ core/shell nanorod array on carbon cloth: a new class of anode for high-performance lithium-ion batteries. Nanoscale 5, 7906-7912 (2013).

21. Wang, Z. et al. Assembling carbon-coated alpha- $\mathrm{Fe}_{2} \mathrm{O}_{3}$ hollow nanohorns on the cnt backbone for superior lithium storage capability. Energy Environ. Sci. 5, 5252-5256 (2012).

22. Fei, H. et al. Preparation of carbon-coated iron oxide nanoparticles dispersed on graphene sheets and applications as advanced anode materials for lithium-ion batteries. Nano Res. 7, 502-510 (2014).

23. Wu, H. et al. Branched $\mathrm{Co}_{3} \mathrm{O}_{4} / \mathrm{Fe}_{2} \mathrm{O}_{3}$ nanowires as high capacity lithium-ion battery anodes. Nano Res. 6, 167-173 (2013).

24. Ren, H. et al. Multishelled $\mathrm{TiO}_{2}$ hollow microspheres as anodes with superior reversible capacity for lithium ion batteries. Nano Lett. 14, 6679-6684 (2014).

25. Li, W. et al. General strategy to synthesize uniform mesoporous $\mathrm{TiO}_{2} /$ graphene/mesoporous $\mathrm{TiO}_{2}$ sandwich-like nanosheets for highly reversible lithium storage. Nano Lett. 15, 2186-2193 (2015).

26. Moitzheim, S. et al. Nanostructured $\mathrm{TiO}_{2} /$ carbon nanosheet hybrid electrode for high-rate thin-film lithium-ion batteries. Nanotechnology 25, 504008 (2014). 
27. Xin, L. et al. Constructing hierarchical submicrotubes from interconnected $\mathrm{TiO} 2$ nanocrystals for high reversible capacity and longlife lithium-ion batteries. Sci. Rep. 4, 4479 (2014).

28. Song, $\mathrm{T}$. et al. $\mathrm{TiO}_{2}$ nanotube branched tree on a carbon nanofiber nanostructure as an anode for high energy and power lithium ion batteries. Nano Res. 7, 491-501 (2014).

29. Wang, X. et al. $\mathrm{TiO}_{2}$ modified FeS Nanostructures with Enhanced Electrochemical Performance for Lithium-Ion Batteries. Sci. Rep. 3, 2007 (2013).

30. Um, J. H. et al. 3D macroporous electrode and high-performance in lithium-ion batteries using $\mathrm{SnO}_{2}$ coated on $\mathrm{Cu}$ foam. Sci. Rep. 6, 18626 (2016).

31. Liu, L. et al. Superior cycle performance and high reversible capacity of $\mathrm{SnO}_{2} /$ graphene composite as an anode material for lithiumion batteries. Sci. Rep. 5, 9055 (2015).

32. Li, Q. et al. Thickness-dependent fracture of amorphous carbon coating on $\mathrm{SnO}_{2}$ nanowire electrodes. Carbon 80, 793-798 (2014).

33. Ren, W. et al. $\mathrm{SnO}_{2} @ \mathrm{Si}$ core-shell nanowire arrays on carbon cloth as a flexible anode for Li ion batteries. J. Mater. Chem. A 1, 13433-13438 (2013).

34. Zhou, W. et al. Epitaxial growth of branched $\alpha-\mathrm{Fe}_{2} \mathrm{O}_{3} / \mathrm{SnO}_{2}$ nano-heterostructures with improved lithium-ion battery performance. Adv. Funct. Mater. 21, 2439-2445 (2011).

35. Choi, S. H. \& Kang, Y. C. One-Pot Facile Synthesis of janus-structured $\mathrm{SnO}_{2}-\mathrm{CuO}$ composite nanorods and their application as anode materials in Li-ion batteries. Nanoscale 5, 4662-4668 (2013).

36. Wang, Y. et al. Nanocrystalline $\mathrm{NiO}$ thin film anode with MgO coating for Li-ion batteries. Electrochim. Acta 48, 4253-4259 (2003).

37. Wang, Y. \& Qin, Q. Z. A Nanocrystalline NiO thin-film electrode prepared by pulsed laser ablation for Li-ion batteries. J. Electrochem. Soc. 149, A873-A878 (2002).

38. Cheng, M. Y. \& Hwang, B. J. Mesoporous carbon-encapsulated $\mathrm{NiO}$ nanocomposite negative electrode materials for high-rate Li-ion battery. J. Power Sources 195, 4977-4983 (2010).

39. Long, H. et al. Growth of hierarchal mesoporous $\mathrm{NiO}$ nanosheets on carbon cloth as binder-free anodes for high-performance flexible lithium-ion batteries. Sci. Rep. 4, 7413 (2014).

40. Wu, M. S. \& Lin, Y. P. Monodispersed macroporous architecture of nickel-oxide film as an anode material for thin-film lithium-ion batteries. Electrochim. Acta 56, 2068-2073 (2011).

41. Sun, X. et al. Three-dimensionally "curved" $\mathrm{NiO}$ nanomembranes as ultrahigh rate capability anodes for Li-ion batteries with long cycle lifetimes. Adv. Energy Mater. 4, 1300912 (2014).

42. Su, D. et al. Mesoporous nickel oxide nanowires: hydrothermal synthesis, characterisation and applications for lithium-ion batteries and supercapacitors with superior performance. Chemistry 18, 8224-8229 (2012).

43. Yuan, L. \& Zhou, G. Enhanced CuO nanowire formation by thermal oxidation of roughened copper. J. Electrochem. Soc. 159, C205-C209 (2012).

44. Filipic, G. \& Cvelbar, U. Copper oxide nanowires: a review of growth. Nanotechnology 23, 194001 (2012).

45. Cheng, S. L. \& Chen, M. F. Fabrication, characterization, and kinetic study of vertical single-crystalline CuO nanowires on $\mathrm{Si}$ substrates. Nanoscale Res. Lett. 7, 119 (2012).

46. Srivastava, H. et al. In-situ energy dispersive $\mathrm{x}$-ray diffraction study of the growth of $\mathrm{CuO}$ nanowires by annealing method. J. Appl. Phys. 114, 144303 (2013).

47. Mumm, F. \& Sikorski, P. Oxidative fabrication of patterned, large, non-flaking CuO nanowire arrays. Nanotechnology 22, 105605 (2011).

48. Lv, S. et al. Hexamethylenetetramine-induced synthesis of hierarchical $\mathrm{NiO}$ nanostructures on nickel foam and their electrochemical properties. J. Alloys Compd. 603, 190-196 (2014).

49. Mukhopadhyay, A. et al. Stress development due to surface processes in graphite electrodes for Li-ion batteries: a first report. Electrochim. Acta. 66, 28-37 (2012).

50. He, Y. \& Hu, H. Analysis of lithium ion concentration and stress in solid electrolyte interphase on the graphite anode. Phys. Chem. Chem. Phys. 17, 23565-23572 (2015).

51. Wu, M. S. \& Chang, H. W. Self-assembly of NiO-coated $\mathrm{ZnO}$ nanorod electrodes with core-shell nanostructures as anode materials for rechargeable lithium-ion batteries. J. Phys. Chem. C 117, 2590-2599 (2013).

52. Guo, W. et al. Multi-Layer CuO@NiO hollow spheres: microwave-assisted metal-organic-framework derivation and highly reversible structure-matched stepwise lithium storage. ACS Nano 9, 11462-11471 (2015).

53. Chen, H. et al. Facile synthesis of $\mathrm{CuO}-\mathrm{NiO}$ nanocomposites with high surface areas and their application for lithium-ion batteries. Micro \& Nano Lett. 8, 544-548 (2013).

54. Lyu, F. et al. Supramolecular hydrogels directed self-assembly of $\mathrm{C}, \mathrm{N}$-doping hollow $\mathrm{CuO}$ as high-performance anode materials for li-ion batteries. J. Name. 00, 1-3 (2012).

55. Xu, X. et al. Preparation of nanoporous $\mathrm{CuO} / \mathrm{Cu}$ composite by dealloy method for high performance lithium-ion batteries. J. Name. 00, 1-3 (2013).

56. Su, D. et al. $\mathrm{CuO}$ single crystal with exposed $\{001\}$ facets - A highly efficient material for gas sensing and Li-ion battery applications. Sci. Rep. 4, 5753 (2014)

\section{Acknowledgements}

This work is supported by the Hierarchical Green-Energy Materials (Hi-GEM) Research Center, Ministry of Science and Technology (MOST 107-3017-F-006-003-, MOST 105-2923-E-006-001-MY3, MOST1072218-E-006-014, MOST 107-2622-8-006-015, MOST 107-2221-E-006-020-MY3 and MOST 107-2221-E-006021-MY3), and Ministry of Education (MOE 1070147306D).

\section{Author Contributions}

Conception and design: Y.W.C. Conducted the experiment(s): S.W.Y. Analysis and interpretation of data: Y.W.C., C.H.C. and Y.C.L. Contribution to discussion: Y.W.C., C.H.C., B.L.P., C.C.C., R.C.W. and C.P.L. Writing of the manuscript: C.H.C. Study supervision: R.C.W. and C.P.L., All authors have reviewed the final manuscript.

\section{Additional Information}

Supplementary information accompanies this paper at https://doi.org/10.1038/s41598-018-36378-0.

Competing Interests: The authors declare no competing interests.

Publisher's note: Springer Nature remains neutral with regard to jurisdictional claims in published maps and institutional affiliations. 
(c) (i) Open Access This article is licensed under a Creative Commons Attribution 4.0 International

License, which permits use, sharing, adaptation, distribution and reproduction in any medium or format, as long as you give appropriate credit to the original author(s) and the source, provide a link to the Creative Commons license, and indicate if changes were made. The images or other third party material in this article are included in the article's Creative Commons license, unless indicated otherwise in a credit line to the material. If material is not included in the article's Creative Commons license and your intended use is not permitted by statutory regulation or exceeds the permitted use, you will need to obtain permission directly from the copyright holder. To view a copy of this license, visit http://creativecommons.org/licenses/by/4.0/.

(C) The Author(s) 2018 